\title{
Why Do Patients With Interstitial Lung Diseases Fail in the ICU? A 2-Center Cohort Study
}

\author{
Gökay Güngör MD, Dursun Tatar MD, Cüneyt Saltürk MD, Pinar Çimen MD, \\ Zuhal Karakurt MD, Cenk Kirakli MD, Nalan Adıgüzel MD, Özlem Ediboğlu MD, \\ Huri Yılmaz MD, Özlem Yazıcıoglu Moçin MD, Merih Balcı MD, and Adnan Yılmaz MD
}

\begin{abstract}
BACKGROUND: Admitting patients with interstitial lung disease (ILD) to the ICU is controversial, due to their associated high mortality when they require invasive mechanical ventilation. We aimed to determine the risk factors for mortality in ILD patients requiring ICU support due to acute respiratory failure. METHODS: An observational cohort study was performed in 2 chest diseases teaching hospitals. We included all ILD patients with acute respiratory failure admitted between 2008 and 2010. Subject demographics, noninvasive ventilation (NIV) and invasive ventilation use, and mortality were obtained from medical records. Subjects receiving NIV were divided based on their continuous or non-continuous demand for NIV. NIV failure was defined as intubation for invasive ventilation, or death during NIV. Cox regression analysis was used to determine the hazard ratio for NIV failure. RESULTS: We enrolled 120 subjects: 71 male, median age 66 years. The types of ILD were idiopathic pulmonary fibrosis $(n=96)$, collagen vascular disease $(n=10)$, silicosis $(n=9)$, drug induced $(n=3)$, and eosinophilic pneumonia $(n=2)$. The median (IQR) Acute Physiology and Chronic Health Evaluation (APACHE II) score was 24 (19-31), and 75 (62.5\%) subjects received NIV on ICU admission, $47(62.7 \%)$ of whom needed continuous NIV. The NIV failure rate was $49.3 \%(n=37)$. The mortality rates of continuous NIV, non-continuous NIV, invasive ventilation, and total ICU were $61.7 \%(29 / 47), 10.7 \%(3 / 28), 89.7 \%(61 / 68), 60 \%(72 / 120)$, respectively. APACHE II > 20 and continuous NIV demand indicated significant risk for NIV failure: hazard ratio 2.77 (95\% CI 1.19-6.45), $P<.02$, and 5.12, (1.44-18.19), $P<.01$, respectively. CONCLUSIONS: Because of higher mortality, physicians should consider invasive ventilation cautiously in the ICU management of ILD patients with acute respiratory failure. NIV may be an option in less severely ill patients with APACHE II score < 20. Key words: ICU; interstitial pulmonary fibrosis; acute respiratory failure; mortality. [Respir Care 2013;58(3):525-531. (C) 2013 Daedalus Enterprises]
\end{abstract}

\section{Introduction}

Pulmonary fibrosis is the end stage of various different interstitial lung diseases (ILDs). ILD can have known and unknown etiologies. Idiopathic pulmonary fibrosis (IPF) is the most common, progressive form of fibrotic inflammatory lung disease of unknown etiology with the median survival time ranging from 3 to 5 years from diagnosis. ${ }^{1-5}$ Although the disease remains stable in some patients, ep-

Correspondence: Zuhal Karakurt MD, Respiratory Intensive Care Unit, Pulmonology Department, Sureyyapasa, Chest Disease and Thoracic Surgery Training and Research Hospital, Soyakyenişehir Manolya Evleri B3/63 Ümraniye, İstanbul 34770 Turkey. E-mail: zuhalkarakurt@ hotmail.com.

DOI: $10.4187 /$ respcare.01734 
isodes of acute respiratory failure (ARF) requiring ICU admission and mechanical ventilation are also observed. ${ }^{6-10}$

In pulmonary fibrosis patients with ARF, both invasive and noninvasive mechanical ventilation (MV) can be considered as therapeutic options, but the benefit of MV is not promising. ${ }^{9}$ With a poor prognosis and higher risk of infection associated with invasive ventilation, noninvasive ventilation (NIV) has a potentially beneficial role. ${ }^{11-14}$ Recently, Molina-Molina and co-workers reported no significant benefit of mechanical ventilation on the prognosis of IPF patients with ARF. ${ }^{15}$ In addition, factors affecting ICU mortality in this group of patients, and the question of how long the support should be given, remain unclear.

In this retrospective observational 2-center cohort study, we evaluated the outcomes of these patients and attempted to gauge which ILD patients with ARF would benefit least from ICU admission.

\section{Methods}

The study design was an observational, retrospective 2-center cohort study and was conducted in 2 tertiary teaching hospitals with a total number of 51 ICU beds (center $A=22$, center $B=29$ ), between January 2008 and December 2010. Two respiratory ICU centers were conducted by pulmonary specialists. The ICU nurse/bed ratio was $1 / 3$. The study was approved by the local ethics committee of the 2 government hospitals.

\section{Subjects}

Previously or newly diagnosed patients with ILD admitted to the ICU with ARF were retrospectively evaluated during the study period. IPF was defined according to the American Thoracic Society/European Respiratory Society consensus statement criteria. ${ }^{3}$ The presence of silicosis and drug induced pulmonary fibrosis was recorded. The subjects' demographics, Acute Physiology and Chronic Health Evaluation (APACHE II) score ${ }^{16}$ on admission to the ICU, the use of invasive ventilation or NIV, ${ }^{17}$ arterial blood gas (ABG) values, routes of feeding (oral, enteral/ parenteral), stay in ICU, immunosuppressive therapy, and mortality were recorded.

\section{Assessment of the Causes of ARF}

ARF was defined as an acute and rapid deterioration in respiratory function and exacerbation of dyspnea within a few days, associated with a deterioration of hypoxemia with a $\mathrm{PaO}_{2} / \mathrm{FIO}_{2}<250 \mathrm{~mm} \mathrm{Hg.}{ }^{3}$ Reasons for ARF were grouped as idiopathic, infection, cardiovascular disorders, pulmonary thromboembolism, and other (eg, spontaneous pneumothorax). These assessments were determined with the aid of clinical, radiological, hemodynamic, and pathol-

\section{QUICK LOOK}

\section{Current knowledge}

Pulmonary fibrosis is the end stage for several interstitial lung diseases. Both noninvasive ventilation (NIV) and invasive ventilation are controversial because the benefit and impact on outcome are suspect. Mortality is high in patients with pulmonary fibrosis requiring invasive ventilation.

\section{What this paper contributes to our knowledge}

Invasive ventilation in subjects with interstitial lung disease was associated with a mortality of $60 \%$. Subjects with less severe disease (Acute Physiology and Chronic Health Evaluation II [APACHE] score < 20) may benefit from noninvasive ventilation. NIV failure was approximately $50 \%$ in the patients who needed continuous NIV and had APACHE II scores $>20$.

ogy results in the medical records for each subject. Pneumonia was clinically diagnosed by the radiographic presence of new or progressive radiological infiltrates, with 2 of: fever, peripheral blood leukocytosis, purulent tracheal secretions, and documented microbiological culture results. ${ }^{18,19}$

\section{Assessment of Treatment With Mechanical Ventilation}

Both respiratory ICU centers followed similar protocols for assessing the demand for mechanical ventilation. The decision to use mechanical ventilation was based on the presence of at least one of the following 2 criteria for respiratory failure: severe dyspnea with marked deterioration of oxygen saturation, or oxygen saturation $<80 \%$ despite a high oxygen flow rate using a high-concentration facial mask (4a, Medical Echo, Ankara, Turkey), or acute alteration of consciousness, with or without marked hypercapnia. ${ }^{17}$

NIV was initiated on respiratory failure with a $\mathrm{PaO}_{2} / \mathrm{FIO}_{2}$ $<250 \mathrm{~mm} \mathrm{Hg}$. NIV was performed by pressure support mode with oro-nasal mask or helmet (4Vent, Rüsch, Mirandola, Italy). Ventilator settings such as pressure support, PEEP, and flow-by trigger were calibrated to target high oxygenation and reduce breathing frequency according to ABG data. The PEEP was adjusted 5-7 $\mathrm{cm} \mathrm{H}_{2} \mathrm{O}$ pressure, due to the high risk of pneumothorax.

We defined subjects according to their NIV demand as continuous and non-continuous. Non-continuous NIV subjects were defined as those able to tolerate the interruption of NIV for feeding. Continuous NIV subjects were defined 


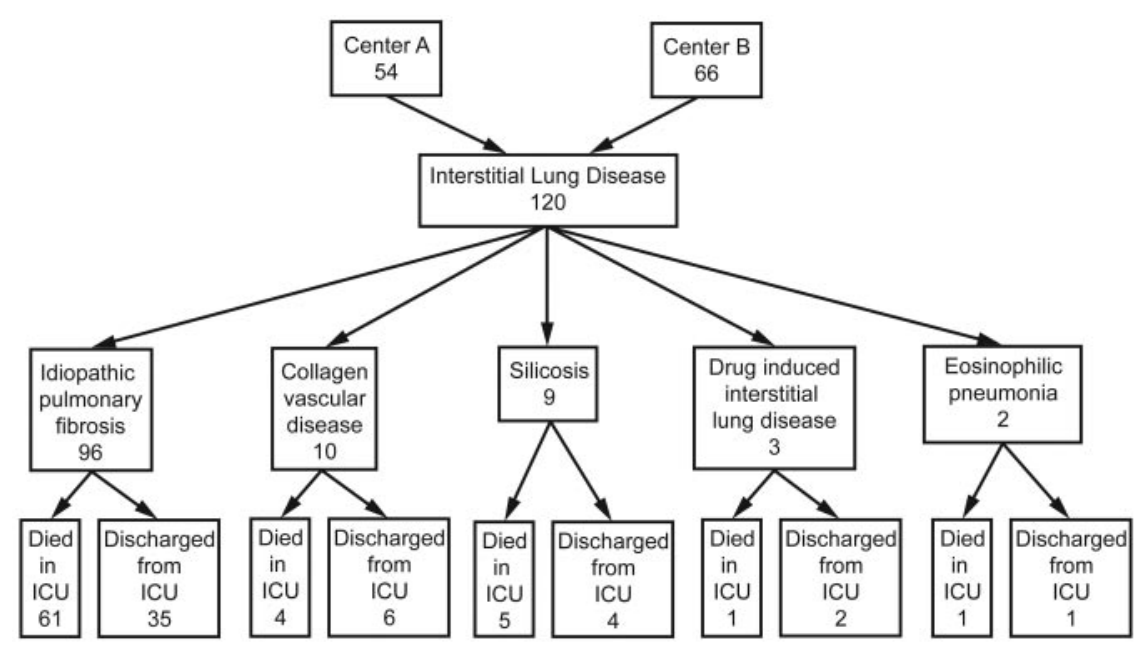

Fig. 1. Outcomes of subjects with interstitial lung diseases in the ICU over a 3 year period.

as subjects who were fed solely via nasogastric tube, or those with total parenteral nutrition due to intolerance of NIV interruption. Subjects were also divided into 2 groups according to their NIV response. The first group comprised those subjects in whom NIV was deemed a success, as defined by not needing intubation and being discharged from the ICU with only NIV support. The second group comprised those subjects in whom NIV was deemed a failure, as defined by the need for intubation, invasive mechanical ventilation, or those subjects who died while on NIV support. NIV contraindications were as follows: cardiovascular instability, cardiac or respiratory arrest, poor adherence with NIV, or Glasgow coma scale score $<10$ (except encephalopathic subjects with hypercapnia treated initially with NIV). ${ }^{17}$ Unless the subject refused intubation, invasive mechanical ventilation was used with any of the following criteria: decreased alertness, signs of respiratory exhaustion on physical examination (use of the accessory muscles of respiration with paradoxical abdominal or thoracic motion), hemodynamic instability, cardiac arrest, or refractory hypoxemia. ABGs were recorded on admission to the ICU. Both centers initially used the pressure control ventilation mode and titrated inspiratory pressure to moderate tidal volume $(6-8 \mathrm{~mL} / \mathrm{kg})$. Both centers also controlled the PEEP level to 5-7 $\mathrm{cm} \mathrm{H}_{2} \mathrm{O}$, in order to prevent pneumothorax.

\section{Statistical Analysis}

Values are expressed as mean $\pm \mathrm{SD}$ for parametric continuous data, and as median (IQR) for non-parametric continuous data. Variables were compared using the Student $t$ test, the Mann-Whitney U test, or the chi-square test where appropriate. All statistical tests were 2 -sided; $P$ values less than .05 were considered statistically significant.
Subject characteristics and ICU data of all survivors, nonsurvivors, and subject groups (NIV success vs NIV failure), were compared. Cox regression analysis was used for risk hazard ratio for NIV failure. We included age, sex, continuous NIV demand and APACHE II score on admission to the ICU in the Cox regression model. KaplanMeier survival analysis was performed for those subjects who initially received NIV. Statistics software (SPSS 15.0, Chicago, IL) was used for statistical analysis.

\section{Results}

A total of 120 subjects diagnosed with interstitial lung disease, as assessed by previous clinical, radiological and pathology results, were included; 15 subjects were diagnosed by lung biopsy. The features of the various ILDs are summarized in Figure 1.

The median (IQR) age of all subjects was 66 years (56-75 y). Long-term oxygen therapy had been previously given to $56(47.1 \%)$ of the subjects. All subjects had severe hypoxemia (median [IQR] $\mathrm{PaO}_{2} / \mathrm{FIO}_{2} 143 \mathrm{~mm} \mathrm{Hg}$ [98-180 mm Hg]), and the majority of subjects had hypercapnia (median [IQR] $\mathrm{PaCO}_{2} 47 \mathrm{~mm} \mathrm{Hg}$ [36$69 \mathrm{~mm} \mathrm{Hg}]$ ). The median (IQR) APACHE II score was 24 (19-31). Reasons for ARF were idiopathic $(n=36,30 \%)$, hypoxia due to pneumonia $(n=71,59.2 \%)$, cardiac diseases $(n=2,1.7 \%)$, spontaneous pneumothorax $(n=8$, $6.7 \%)$, and pulmonary embolism $(n=3,2.5 \%)$. The management of respiratory failure on admission to ICU, and mortality are summarized in Figure 2 and Figure 3. The initial respiratory support of 120 ILD subjects were as follows: NIV in 75 subjects, invasive ventilation in 41 subjects, and pure nasal oxygen in 4 subjects. Overall, the mortality rate in ICU was $60 \%(n=72)$. The outcomes of the subjects with continuous and non-continuous demand 


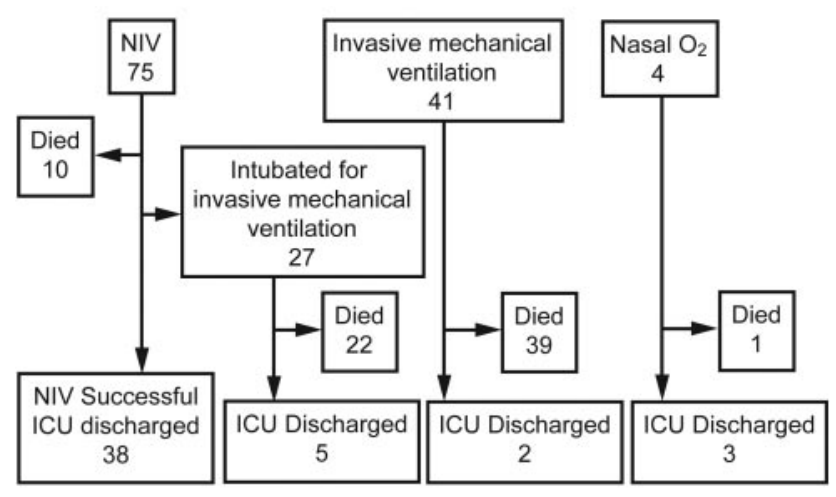

Fig. 2. Respiratory support of subjects with interstitial lung diseases on admission and until discharge from ICU. NIV = noninvasive ventilation.

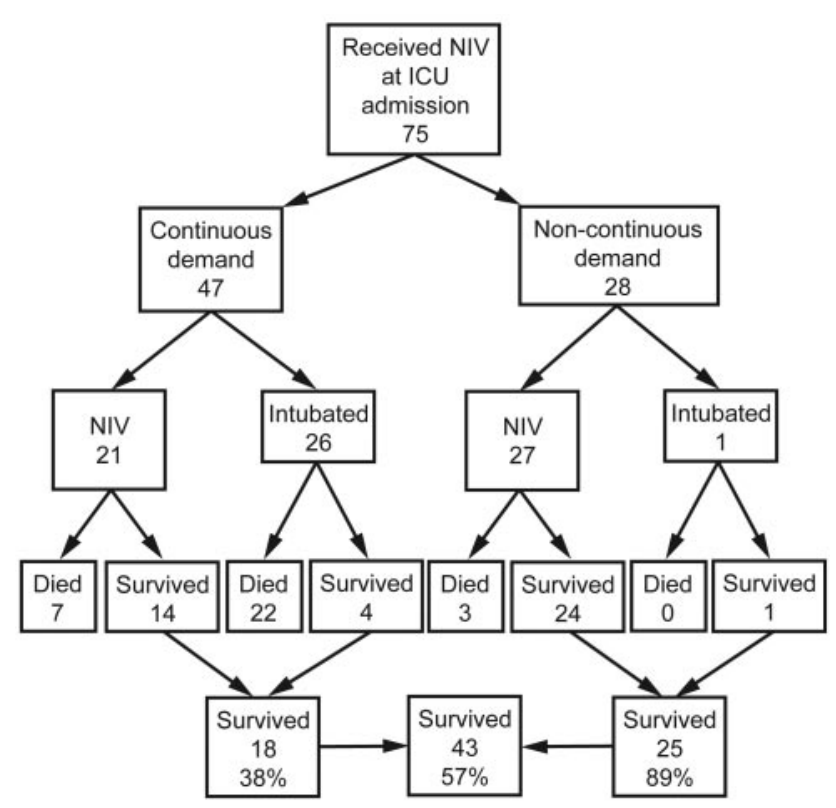

Fig. 3. Noninvasive ventilation (NIV): continuous versus noncontinuous NIV demand groups.

for NIV are shown in Figure 3. There were 28 subjects with non-continuous NIV and 47 subjects with continuous NIV, and the requirement for invasive ventilation was 26/47 and $1 / 28$, respectively (see Fig. 3). The mortality rate of subjects who initially received invasive ventilation was 39/41 (see Fig. 2).

We compared the survivors and non-survivors in the ICU according to age, sex, body mass index, and the presence of chronic comorbid diseases. These results are summarized in Table 1. Diabetes and cardiac disease was significantly higher in survivors $(20.8 \%$ vs $12.5 \%, P=.046$, $35.4 \%$ vs $13.8 \%, P=.005$, respectively). Body mass index data were available for only 46 subjects (survivors $n=18$, non-survivors $n=28$ ), and there were no significant differences (see Table 1).
Survivors and non-survivors were compared according to ICU data (Table 2). APACHE II scores, ABG values on admission to the ICU, the number of subjects who received NIV, duration of NIV, and the stay in ICU are shown in Table 2.

Non-survivors had a shorter hospital stay than survivors ( $6 \mathrm{~d}$ vs $12 \mathrm{~d}, P<.001$ ), but the values for stay in the ICU were similar. Both NIV and invasive ventilation durations were similar for survivors and non-survivors. The number of survivors in those subjects receiving NIV was higher (89.6\% vs $44.4 \%, P<.001$ ), but the use of invasive ventilation was higher in the non-survivors than survivors $(84.7 \%$ vs $14.6 \%, P<.001)$. The APACHE II score was significantly higher in non-survivors (29 vs $19, P<.001$ ), and $\mathrm{ABG}$ analyses were similar for survivors and nonsurvivors.

Seventy-five subjects who initially received NIV were further grouped according to their NIV response (38 NIV success subjects, 37 NIV failure subjects). Of the 75 subjects, 27 (36.0\%) were intubated for invasive ventilation, and the median (IQR) invasive ventilation duration was $3 \mathrm{~d}(2-4 \mathrm{~d})$. Twenty-two $(81.4 \%)$ died in the ICU. Ten subjects died during NIV, and the total mortality rate was $42.6 \%(n=32)$ for those subjects who initially received NIV. The subject characteristics and ICU outcomes are summarized in Table 3.

To determine the risk factors for NIV failure we used Cox regression analysis. We included age, sex, continuous NIV demand, and APACHE II score on admission to the ICU in the regression model. Two risk factors were found to be significant for NIV failure of ILD in the ICU: an APACHE II score $>20$ (hazard ratio $2.77,95 \%$ CI $1.19-$ $6.45, P<.02$ ), and continuous NIV demand (hazard ratio $5.12,95 \%$ CI $1.44-18.19, P<.01)$.

A Kaplan Meier curve for the probability of NIV failure relative to continuous NIV and stratified for an APACHE II score $>20$ is shown in Figure 4 .

\section{Discussion}

The primary finding in this study was that the survival of subjects with ILD, who required invasive mechanical ventilation, was very poor. On the other hand, the survival of ILD subjects who received NIV was higher, especially in subjects with lower APACHE II scores $(<20)$ and a non-continuous demand for NIV in the ICU.

Of the ILDs, IPF is a progressive and fatal disease. The presence of refractory hypoxemia and marked tachypnea indicates the end stage of the disease and causes ARF in about $40 \%$ of patients. ${ }^{15}$ ARF in these patients is characterized by a deep hypoxemia in the first stage and carbon dioxide retention due to respiratory fatigue in the second stage. In the present study, all ILD subjects had hypoxemia, and the majority had hypercapnia. The median age 
Table 1. Subject Characteristics Relative to ICU Mortality

\begin{tabular}{lccr}
\hline \hline & $\begin{array}{c}\text { Survivors } \\
(n=48)\end{array}$ & $\begin{array}{c}\text { Non-survivors } \\
(n=72)\end{array}$ & $P$ \\
\hline Age, mean $\pm \mathrm{SD}$ y & $61.6 \pm 13.2$ & $65.7 \pm 14.5$ & .12 \\
Female/male, no. & $24 / 24$ & $25 / 47$ & .09 \\
Body mass index, mean $\pm \mathrm{SD} \mathrm{kg} / \mathrm{m}^{2}$ & $22.4 \pm 4.5$ & $23.3 \pm 5.4$ & .54 \\
Long-term $\mathrm{O}_{2}$ therapy & $27(56.3)$ & $29(40.3)$ & .09 \\
Comorbidity & $30(62.5)$ & $42(58.3)$ & .71 \\
Diabetes mellitus & $10(20.8)$ & $6(12.5)$ & .046 \\
Cardiac diseases & $17(35.4)$ & $10(13.8)$ & .005
\end{tabular}

Values are number and percent unless otherwise indicated.

Table 2. ICU Outcomes for Patients With Interstitial Lung Disease

\begin{tabular}{|c|c|c|c|}
\hline & $\begin{array}{l}\text { Survivors } \\
(n=48)\end{array}$ & $\begin{array}{l}\text { Non-survivors } \\
\quad(n=72)\end{array}$ & $P$ \\
\hline Hospital stay, d & $12(8-18)$ & $6(3-12)$ & .001 \\
\hline ICU stay, $d$ & $5(3-7)$ & $6(3-12)$ & .12 \\
\hline NIV duration, $\mathrm{d}$ & $4(2-7)$ & $4(2-6)$ & .72 \\
\hline Invasive ventilation duration, $\mathrm{d}$ & $5(2-6)$ & $2(1-4)$ & .24 \\
\hline NIV, no. (\%) & $43(89.6)$ & $32(44.4)$ & .001 \\
\hline Invasive ventilation, no. (\%) & $7(14.6)$ & $61(84.7)$ & .001 \\
\hline APACHE II score & $19(16-23)$ & $29(23-36)$ & .001 \\
\hline $\mathrm{pH}$ & $7.39(7.30-7.46)$ & $7.39(7.31-7.47)$ & .91 \\
\hline $\mathrm{PaCO}_{2}, \mathrm{~mm} \mathrm{Hg}$ & $46.6(35.7-67.0)$ & $44.8(32.4-66.9)$ & .43 \\
\hline $\mathrm{PaO}_{2} / \mathrm{FIO}_{2}, \mathrm{~mm} \mathrm{Hg}$ & $160(100-196)$ & $139(91-168)$ & .056 \\
\hline NIV = noninvasive mechanical ventilation & & & \\
\hline
\end{tabular}

of our subjects was 66 years, and a male predominance was observed, concordant with the course of the disease.

Rangappa and Moran similarly reported that the acute deterioration that led to ICU admission was attributed to pneumonia in $42 \%$ of cases. ${ }^{20}$ These patients were mostly on corticosteroid therapy, showed purulent secretion, and had a fever, although these features may be nonspecific.

Also, it can be difficult to use radiographic changes as a differential diagnostic tool to distinguish disease progression and pneumonic infiltration. In addition, Blivet et al reported that early diagnosis and treatment of infection in end stage IPF patients admitted to ICU with ARF does not change the outcome. ${ }^{10}$

The effectiveness of MV on prognosis of IPF patients presenting with ARF is controversial. Stern et al claim that using invasive ventilation and NIV in IPF patients should be restricted to patients in whom lung transplantation can be performed within a few days following MV treatment. ${ }^{9}$ On the other hand, Yokoyama and colleagues claim that NIV is a viable option for the respiratory management of exacerbation of IPF. ${ }^{21}$ In our study, invasive ventilation was used significantly more in the nonsurvivor group, while, conversely, NIV was used more in the survivor group. NIV seemed to be an effective treatment method for preventing intubation and mortality. In the present study, NIV was successful in the majority of ILD subjects who had an APACHE II score $<20$. However, the need for intubation and mortality rate was higher $(89.2 \%)$ in subjects with a continuous NIV demand.

Nava and Rubini measured the respiratory mechanics during MV in 7 patients with IPF and found that increased elastance and the resistance of the respiratory system may contribute to poor response to treatment with MV. ${ }^{22}$ Fernández-Pérez and co-workers also showed a poor outcome with high PEEP, as it may overinflate relatively intact lung units. It also has no effect on fibrotic, unrecruitable regions, and thus promotes ventilator interaction lung injury in patients with ILDs. ${ }^{23}$ In the present study we avoided high PEEP, due to the risk for pneumothorax.

There are some limitations in our study. IPF diagnosis was not confirmed histologically in all subjects. The effect 
Why Do Patients With Interstitial Lung Diseases Fail in the ICU?

Table 3. Subject Characteristics and ICU Data Relative to NIV Response

\begin{tabular}{|c|c|c|c|}
\hline & $\begin{array}{l}\text { NIV Success } \\
\quad(n=38)\end{array}$ & $\begin{array}{l}\text { NIV Failure } \\
(n=37)\end{array}$ & $P$ \\
\hline Age, mean $\pm \mathrm{SD}$ y & $61.9 \pm 14.1$ & $65.6 \pm 13.2$ & .24 \\
\hline Male/female, no. & $19 / 19$ & $21 / 16$ & .56 \\
\hline Body mass index, mean $\pm \mathrm{SD} \mathrm{kg} / \mathrm{m}^{2}$ & $22.5 \pm 4.6$ & $23 \pm 5.2$ & .73 \\
\hline \multicolumn{4}{|l|}{ Interstitial Lung Disease, no. (\%) } \\
\hline Idiopathic & $28(73.7)$ & $28(75.7)$ & .99 \\
\hline Collagenous vascular & $4(10.5)$ & $3(8.1)$ & \\
\hline Silicosis & $4(10.5)$ & $4(10.8)$ & \\
\hline Drug induced & $1(2.6)$ & $1(2.7)$ & \\
\hline Eosinophilic pneumonia & $1(2.6)$ & $1(2.7)$ & \\
\hline Comorbidity, no. (\%) & $21(55.3)$ & $25(67.6)$ & .27 \\
\hline Cardiovascular disease, no. (\%) & $14(37.8)$ & $12(32.4)$ & .62 \\
\hline Diabetes mellitus, no. (\%) & $9(23.7)$ & $4(10.8)$ & .22 \\
\hline Long-term $\mathrm{O}_{2}$ therapy, no. (\%) & $23(60.5)$ & $19(51.4)$ & .42 \\
\hline \multicolumn{4}{|l|}{ ICU Data } \\
\hline ICU days, median (IQR) d & $5(3-7)$ & $6(4-10)$ & .050 \\
\hline Hospital days, median (IQR) d & $12(8-18)$ & $9(6-15)$ & .051 \\
\hline NIV days, median (IQR) d & $5(2-7)$ & $4(2-6)$ & .53 \\
\hline Continuous NIV, no. (\%) & $14(36.8)$ & $33(89.2)$ & .001 \\
\hline APACHE II score on ICU admission, median (IQR) & $18(16-20)$ & $26(21-30)$ & .001 \\
\hline $\mathrm{pH}$, median (IQR) & $7.39(7.33-7.46)$ & $7.38(7.29-7.47)$ & .63 \\
\hline $\mathrm{PaCO}_{2}$, median (IQR) mm Hg & $47.9(35.7-67.0)$ & $44.8(32.8-68.2)$ & .55 \\
\hline $\mathrm{PaO}_{2}$, median (IQR) $\mathrm{mm} \mathrm{Hg} / \mathrm{FIO}_{2}$ & $164(104-196)$ & $143(98-170)$ & .24 \\
\hline $\mathrm{HCO}_{3}^{-}$, median $(\mathrm{IQR}) \mathrm{mmol}$ & $29.3(24.0-34.0)$ & $27.4(22.9-35.6)$ & .25 \\
\hline \multicolumn{4}{|l|}{ Reason for Acute Respiratory Failure, no. (\%) } \\
\hline Idiopathic & $15(39.5)$ & $13(35.1)$ & .31 \\
\hline Pulmonary infection & $21(55.3)$ & $24(64.9)$ & \\
\hline Cardiac disease & $2(5.3)$ & $0(0)$ & \\
\hline
\end{tabular}

$\overline{\mathrm{NIV}}=$ noninvasive mechanical ventilation

APACHE $=$ Acute Physiology and Chronic Health Evaluation
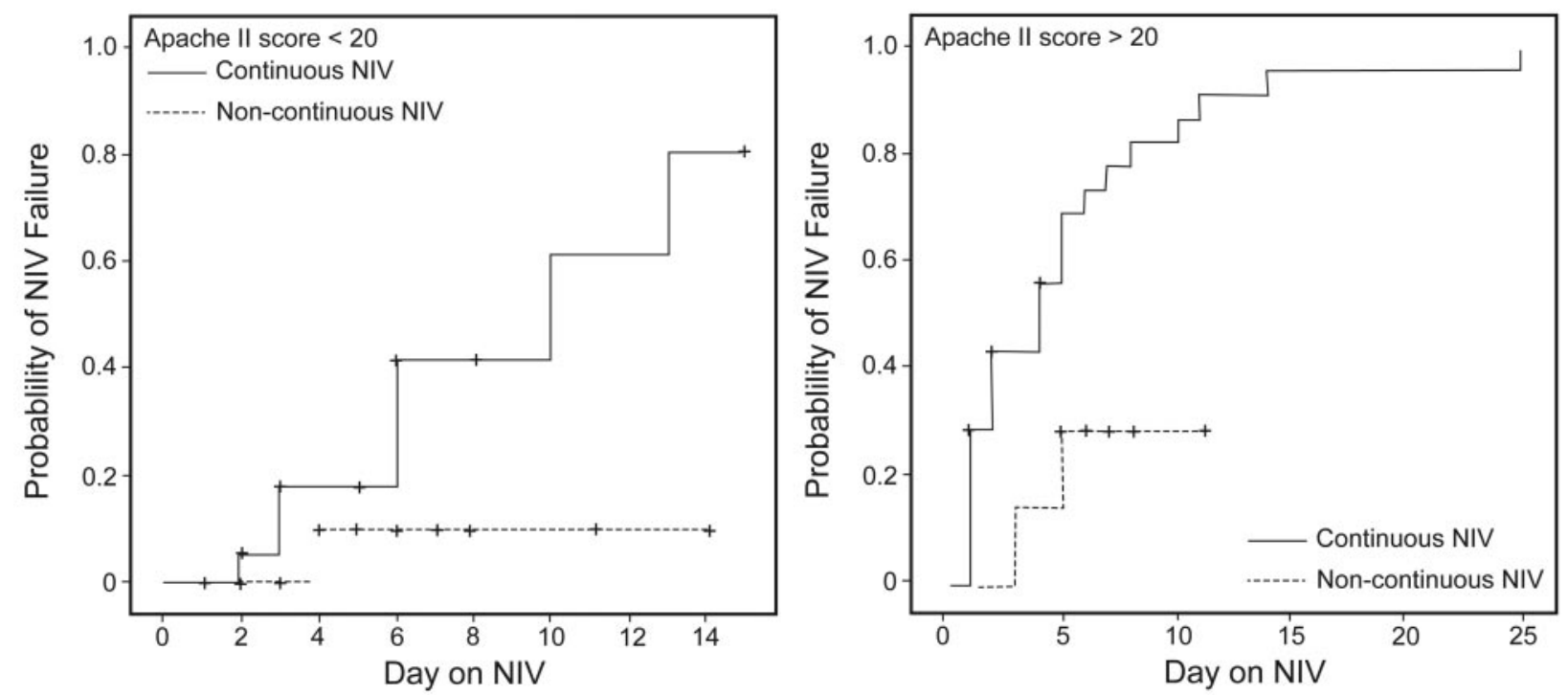

Fig. 4. Kaplan-Meier curve for the probability of noninvasive ventilation (NIV) failure relative to continuous use of NIV and stratified for Acute Physiology and Chronic Health Evaluation (APACHE II) score $(P=.003)$. 


\section{Why Do Patients With Interstitial Lung Diseases Fail in the ICU?}

of lung transplantation on mortality cannot be fully examined in IPF patients admitted to the ICU, because lung transplantation was not routinely performed.

\section{Conclusions}

In conclusion, we found that in ILD subjects admitted to the ICU due to ARF, prognosis is poor despite palliative improvement with NIV. This study result may assist physicians when it comes to making a decision on invasive ventilation. It would appear that invasive ventilation is not helpful for patients who have a continuous NIV demand and whose APACHE II score is high. NIV may be an option in less severe patients with APACHE II score $<20$. Physicians should discuss with these patients and their relatives the high mortality risk (especially for invasive ventilation), and the level and degree of life support and long-term prognosis, prior to admission to ICU.

\section{ACKNOWLEDGMENTS}

The authors would like to acknowledge and thank the American Thoracic Society Methods in Epidemiologic, Clinical, and Operations Research (MECOR) Program for assistance with this research and, in particular, Dr Ahmet Ugur Demir.

\section{REFERENCES}

1. Panos RJ, Mortenson RL, Niccoli SA, King TE. Clinical deterioration in patients with idiopathic pulmonary fibrosis: causes and assessment. Am J Med 1990;88(4):396-404.

2. Hubbard R, Johnston I, Britton J. Survival in patients with cryptogenic fibrosing alveolitis: a population-based cohort study. Chest 1998;113(2):396-400

3. American Thoracic Society, European Respiratory Society. Idiopathic pulmonary fibrosis: diagnosis and treatment. International Consensus Statement. Am J Respir Crit Care Med 2000;161(2 pt 1): 646-664.

4. Turner-Warwick M, Burrows B, Johnson A. Cryptogenic fibrosing alveolitis: clinical features and their influence on survival. Thorax 1980;35(3):171-180.

5. Wells AU, du Bois RM. Prediction of disease progression in idiopathic pulmonary fibrosis. Eur Respir J 1994;7(4):637-639.

6. Kondoh Y, Taniguchi H, Kawabata Y, Yokoi T, Suzuki K, Takagi K. Acute exacerbation in idiopathic pulmonary fibrosis. Analysis of clinical and pathologic findings in three cases. Chest 1993;103(6): 1808-1812.

7. Martinez FJ, Safrin S, Weycker D, Starko KM, Bradford WZ, King TE Jr, et al; IPF Study Group. The clinical course of patients with idiopathic pulmonary fibrosis. Ann Intern Med 2005;142(12 Pt 1): 963-967.

8. Hyzy R, Huang S, Myers J, Flaherty K, Martinez F. Acute exacerbation of idiopathic pulmonary fibrosis. Chest 2007;132(5):1652-1658.

9. Stern JB, Mal H, Groussard O, Brugière O, Marceau A, Jebrak G, Fournier M. Prognosis of patients with advanced idiopathic pulmo- nary fibrosis requiring mechanical ventilation for acute respiratory failure. Chest 2001;120(1):213-219.

10. Blivet S, Philit F, Sab JM, Langevin B, Paret M, Guérin C, Robert D. Outcome of patients with idiopathic pulmonary fibrosis admitted to the ICU for respiratory failure. Chest 2001;120(1):209-212.

11. Antonelli M, Conti G, Esquinas A, Montini L, Maggiore SM, Bello $\mathrm{G}$, et al. A multiple-center survey on the use in clinical practice of noninvasive ventilation as a first-line intervention for acute respiratory distress syndrome. Crit Care Med 2007;35(1):18-25.

12. Hilbert G, Gruson D, Vargas F, Valentino R, Gbikpi-Benissan G, Dupon $\mathrm{M}$, et al. Noninvasive ventilation in immunosuppressed patients with pulmonary infiltrates, fever, and acute respiratory failure. N Engl J Med 2001;344(7):481-487.

13. Fumeaux T, Rothmeier C, Jolliet P. Outcome of mechanical ventilation for acute respiratory failure in patients with pulmonary fibrosis. Intensive Care Med 2001;27(12):1868-1874.

14. Tomii K, Seo R, Tachikawa R, Harada Y, Murase K, Kaji R, et al. Impact of noninvasive ventilation (NIV) trial for various types of acute respiratory failure in the emergency department; decreased mortality and use of the ICU. Respir Med 2009;103(1):67-73.

15. Molina-Molina M, Badia JR, Marín-Arguedas A, Xaubet A, Santos MJ, Nicolás JM, et al. [Outcomes and clinical characteristics of patients with pulmonary fibrosis and respiratory failure admitted to an intensive care unit. A study of 20 cases]. Med Clin (Barc) 2003; 121(2):63-67. Article in Spanish.

16. Knaus WA, Draper EA, Wagner DP, Zimmerman JE. APACHE II: a severity of disease classification system. Crit Care Med 1985; 13(10):818-829.

17. American Thoracic Society, European Respiratory Society, European Society of Intensive Care Medicine, Société de Réanimation de Langue Française. International Consensus Conference in Intensive Care Medicine: noninvasive positive pressure ventilation in acute respiratory failure. Approved by the ATS Board of Directors, December 2000. Am J Respir Crit Care Med 2001;163(1):283-291.

18. Mandell LA, Wunderink RG, Anzueto A, Bartlett JG, Campbell GD, Dean NC et al; Infectious Diseases Society of America; American Thoracic Society. Infectious Diseases Society of America/American Thoracic Society consensus guidelines on the management of community-acquired pneumonia in adults. Clin Infect Dis 2007;44 (Suppl 2):S27-S72.

19. American Thoracic Society; Infectious Diseases Society of America. Guidelines for the management of adults with hospital-acquired, ventilator-associated, and healthcare-associated pneumonia. Am J Respir Crit Care Med 2005;171(4):388-416.

20. Rangappa P, Moran JL. Outcomes of patients admitted to the intensive care unit with idiopathic pulmonary fibrosis. Crit Care Resusc 2009;11(2):102-109.

21. Yokoyama T, Kondoh Y, Taniguchi H, Kataoka K, Kato K, Nishiyama $\mathrm{O}$, et al. Noninvasive ventilation in acute exacerbation of idiopathic pulmonary fibrosis. Intern Med 2010;49(15):1509-1514.

22. Nava S, Rubini F. Lung and chest wall mechanics in ventilated patients with end stage idiopathic pulmonary fibrosis. Thorax 1999; 54(5):390-395.

23. Fernández-Pérez ER, Yilmaz M, Jenad H, Daniels CE, Ryu JH, Hubmayr RD, Gajic O. Ventilator settings and outcome of respiratory failure in chronic interstitial lung disease. Chest 2008;133(5): 1113-1119. 